\title{
Regional Climate Effects of Conversion from Grassland to Forestland in Southeastern China
}

\author{
Rui Yu, ${ }^{1}$ Xinsheng Wang, ${ }^{1}$ Zhe Yan, ${ }^{1}$ Haiming Yan, ${ }^{2}$ and Qunou Jiang ${ }^{3}$ \\ ${ }^{1}$ Faculty of Resources and Environmental Science, Hubei University, Wuhan 430062, China \\ ${ }^{2}$ State Key Laboratory of Water Environment Simulation, School of Environment, Beijing Normal University, Beijing 100875, China \\ ${ }^{3}$ School of Soil and Water Conservation, Beijing Forestry University, Beijing 100038, China \\ Correspondence should be addressed to Rui Yu; yur_dls@163.com
}

Received 19 June 2013; Accepted 28 August 2013

Academic Editor: Xiangzheng Deng

Copyright (C) 2013 Rui Yu et al. This is an open access article distributed under the Creative Commons Attribution License, which permits unrestricted use, distribution, and reproduction in any medium, provided the original work is properly cited.

\begin{abstract}
The land-use and land-cover change (LUCC) is the synthetic result of natural processes and human activities; it largely depends on the surface vegetation conditions, and the mutual conversion among land cover types can accelerate or alleviate the regional and global climate changes. Aiming at analyzing the regional climatic effects of the conversion from grassland to forestland, especially in the long term perspective, we carried out the comparison simulation using the Weather Research and Forecasting (WRF) Model in Fujian province, results indicated that this conversion had a significant influence on the regional climate; the annual average temperature decreased by $0.11^{\circ} \mathrm{C}$ and the annual average precipitation increased by $46 \mathrm{~mm}$ after $11.2 \%$ of the grassland was converted into the forestland in the study area from 2000 to 2008. In the future (form 2010 to 2050), the conversion from grassland to forestland is significant under two representative concentration pathways (RCPs) (RCP6 and RCP8.5); the spatial pattern of this conversion under the two scenarios is simulated by dynamic of land system (DLS); then, the regional climate effects of the conversion are simulated using WRF model.
\end{abstract}

\section{Introduction}

Under the coupled impact of natural processes and human activities over the past century, the global vegetation system has changed correspondingly, which in turn influenced the regional and global climate. The nature of the vegetation affects the surface fluxes of radiation, heat, moisture, and momentum, so modifying the vegetation cover can change the lower boundary conditions of the atmosphere and hence impact the climate [1]. Besides, changes in vegetative cover, especially the change of vegetation types, are associated with changes in plants' morphology and physiology, which could, in the absence of other force, alter the surface fluxes and consequently the climate both at regional and global scales [2]. In addition, forests and grasses are the most two typical vegetation types on the Earth; however, mankind has significantly changed the Earth surface by transforming natural ecosystems (forests and grasslands) [3]. Furthermore, the conversion of forestland and grassland plays an important role in the climate system, and redistributions of forest and other vegetation (due, e.g., to extensive logging) could initiate important climate feedbacks $[4,5]$. And a significant difference in surface parameter (such as albedo) between forest and grassland results in reduced absorbed radiation for the grasslands, especially during the snow hawing season (spring) [6]. Also, a forested landscape generally has a lower surface albedo than grassland, particularly in conditions of lying snow when shortwave radiation is trapped by multiple reflections within the forest canopy [7]. In fact, the assessment reports of Intergovernmental Panel on Climate Change (IPCC) specifically took agriculture, forestry, and other land use (AFOLU) as a major path to slow the process of global climate change [8], and the research on the impact of forestland and grassland transition on climate is of great significance to find the optimal way to mitigate the climate change.

Numerous studies have reported the climate impact of vegetation changes such as deforestation and grassland degradation at different scales. However, there is still little known about the impact of large scale conversion from 
grassland to forestland on climate, especially the scale and degree it may bring about in the future. The deforestation experiments with Atmospheric General Circulation Models (AGCMs) generally agreed in significant cooling in the spring season within the models and argued that different vegetation cover plays the most significant role in determining the climate-vegetation state of the region $[9,10]$. Further studies carried out in the experiments with the modified Community Climate Model (CCM2) and prescribed Sea Surface Temperature (SST) showed a significant summer cooling effect of grass and forest cover changes on the climate in the USA [11]. And the cooling was also observed in a simulation using a nested mesoscale model in northeast Colorado [12] and in the central plains [13]. In addition, experiments with the Hadley Centre climate model HadCM3 with prescribed SST showed that historical vegetation cover change results in a reduction in midlatitude annual mean temperatures within the model [14]. And extreme scenarios over Amazonia replacing tropical forests with grass lead to warmer, drier climates in several studies [15-17]. Since 1990s, numerical simulations of impact of vegetation changes on climate in China or East Asia have been conducted by Chinese scientists; results showed that the regional temperature, precipitation, and other indicators have been obviously influenced by the change, which could even affect the summer monsoon intensity of Asia in the heavily changed regions [18-20]. However, due to the various scales and degrees of forestland and grassland change and different models that had been used, the simulation results were in poor comparability. Meanwhile, the limited calculation condition has shorter integration time of simulation, and the result cannot reflect the long term climate effect triggered by the change, especially the medium and long term climate effects in the future.

How to find a systematic quantitative way to explore the future climate effects caused by the conversion from grassland to forestland? The comparative model experiments need to be carried out. In this paper, we used the WRF model to quantify the regional climate effect triggered by the conversion from grassland to forestland in Fujian province of southeast China. Based on the RCPs scenario data, future land transition of forestland from grassland in the study area was simulated by using Dynamic of Land System (DLS) model, and then, the space and time scales of regional climate effects were analyzed.

\section{Data and Methodology}

2.1. Study Area. The southeastern coast of China is one of the top lever regions with abundant water, heat, and sunlight resources. It plays an important role in participating in the globalization and the Pacific rim economic circle in China, which occupies about $5.33 \%$ of the land area and less than $21 \%$ of the national population the area and created $35.7 \%$ of national GDP and $70 \%$ of the total import and export [21]. With the development of economy and the policy implementation such as "returning farmland to forest" ecological engineering project, the area of forestland expended sharply, especially in Fujian province, which is

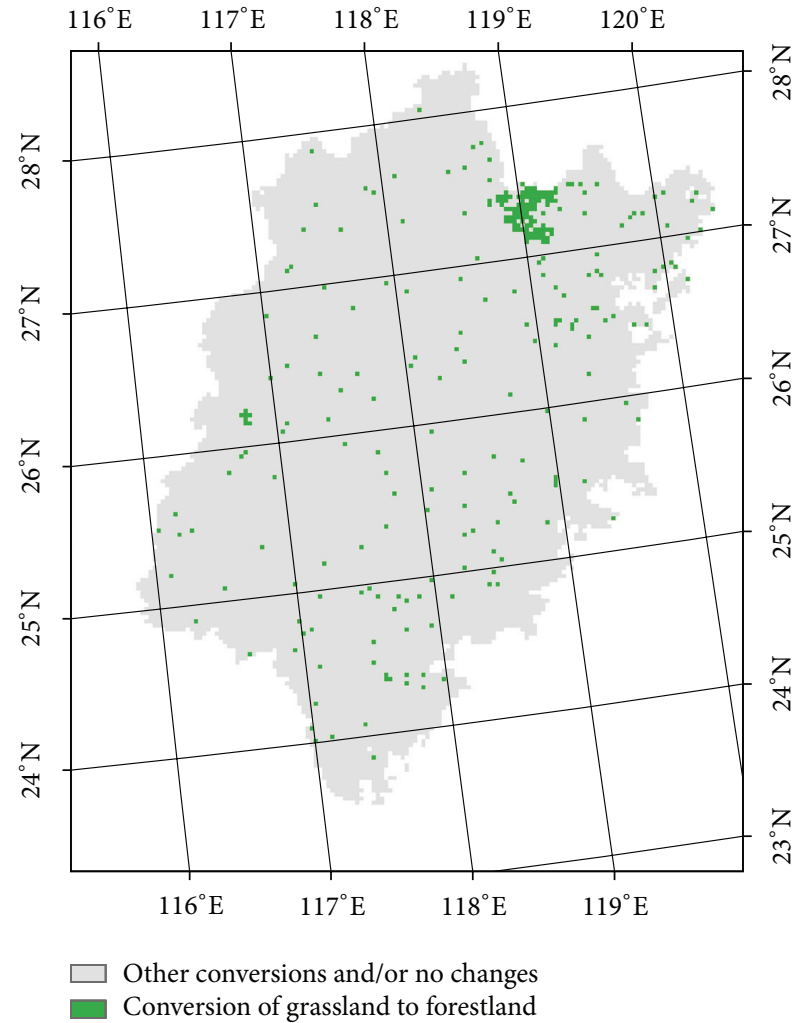

Figure 1: Pattern of the conversion (measured in $3 \mathrm{~km}$ ) from grassland to forestland in Fujian province, 2000-2008.

the most typical afforestation region in China. The forest coverage rate of Fujian is the highest in China, reaching $62.96 \%$ in 2005 [22]. In addition, Fujian is the main region of conversion of forestland from grassland in China [23], and the conversion from grassland to forestland is obvious (Figure 1). Statistical analysis indicated that during 2000$2008,11.2 \%$ of the grassland had been converted into forestland, accounting for $73 \%$ of the total area of forest expansion. Besides, the dominated humid middle and south subtropical maritime monsoon climate, with various heat resources, and plenty water resources played an auxiliary role in the conversion process. In 2005, the forest coverage rate in Fujian had reached $62.96 \%$, which was one of the highest forest coverage rates in the nation. In addition, the most part of grassland in Fujian province is the secondary degenerative environment, which evolves from wasteland after the forest system damaged, and thus, it is beneficial for the conversion from grassland to forestland.

2.2. Data Sources. The lateral boundary force data was mainly derived from NCEP FNL and NCEP/NCAR reanalysis data sets. Forecasting data was derived from the multimodal data of WCRP's Coupled Model Intercomparison Project phase 5 (CMIP5). Chinese National Climate Center had finished the downscaling work of multimodal simulation datasets, which was unified to the same resolution and had been used to undertake the numerical simulation in the eastern Asia. The weighted average reliability value was used to 
undertake the multimodel ensemble (MME); then the annual and monthly average data was made for 2000-2050, namely, climate change forecast data set in China. Data resolution was $1^{\circ} \times 1^{\circ}$, which only included the continental land, with spatial scale of $15.5^{\circ}-55.5^{\circ} \mathrm{N}$ and $72^{\circ} \sim 135^{\circ} \mathrm{E}$.

Land cover data was extracted from the Chinese subset of the Global Land Cover Characteristics database which was developed based on Landsat-TM scenes for 1999/2000 and the Chinese subset of the MODIS land cover data product in 2008. The two datasets have the spatial resolution of $1 \times 1 \mathrm{~km}^{2}$ and an overall accuracy of $81 \%[24,25]$. DLS simulation requires spatial data of natural environment conditions such as climate, elevation, slope, plain area percentage, soil properties, and the geographic data; thereinto, RCPs data was derived from land use harmonized data products (http://luh.umd.edu/data.php), and the climate observation data was acquired from records of 23 weather stations of the National Meteorological Information Center of China, including the moderate average annual rainfall during 20002008. Slope, aspect, and plain area ratio data were extracted from elevation data based on 1:250000 digital elevation model (DEM) for each $1 \times 1 \mathrm{~km}^{2}$ grid. Soil property data came from the second national soil census, and by using Kriging interpolation method, the spatial distribution of soil property was acquired. Regional condition data included the distance of each grid center to highway, provincial highway, main roads, and the provincial capital, and those artery traffic distribution data were derived from the national 1:250000 fundamental geographic maps by using distance measuring tools.

2.3. Estimation Model of Climate Effects. The regional influence of the conversion from grassland to forestland could be described by effect index (EI), which is defined as follows:

$$
\mathrm{EI}(x)=\frac{A_{\text {change }}(x)}{A_{\text {forest }}},
$$

where $x$ is any meteorological parameter such as annual average temperature, precipitation, water vapor mixing ratio or wind speed. $A_{\text {change }}(x)$ is the grid number within the region where $x$ changed and $A_{\text {forest }}$ is grid number of the area converted from grassland to forestland; both of them are calculated at the regional scale, and a bigger EI index reflects a higher efficiency of its climate effect.

We used two nested grids with the spatial resolutions (grid numbers) of $3 \mathrm{~km}(162 \times 177)$. The vertical grid consisted of 35 full sigma levels from the surface to $100 \mathrm{hPa}$, of which the lowest 13 levels were below $1 \mathrm{~km}$ to show a finer resolution in the planetary boundary layer. Both the initial and the boundary conditions were from the National Centers for Environmental Predictions Operational Global Final Analyses on a $1.0^{\circ} \times 1.0^{\circ}$ grid. The simulations were divided into two stages. Firstly, simulation was integrated for 8 years from January 1, 2000, to December 31, 2008. The initial 15-day period was considered as a spin-up period to minimize the effect of the initial conditions. In the control experiment, the land cover data were updated from the 2008 MODIS satellite observations to represent current land cover conditions (TGF case). For the sensitivity experiment, all newly expended forest cover from grass land during 20002008 in domain 2 was replaced by grassland, which is the most common land cover type surrounding the forest area in the simulated domain (NOTGF case). These two cases were compared to analyze the influence of historical conversion from grassland to forestland (2000-2008) in the Fujian. Secondly, we were moving on to the future stage, which was simulated from January 1, 2010, to December 31, 2050, and based on the hypothesis that the future climate effect simulation of the land-use and land-cover change would be reliable as that of the historical one, the newly expended forestland from grassland was updated from the results of DLS simulation to represent future forestland transition from grassland in the NOTFG case. The parameterization schemes used for the two stages are as follows: Noah land surface processes, CAM3 radiative scheme [26], WSM 3-class simple icemicrophysical scheme [27], Grell 3D cumulus convection schemes [28], and YSU boundary layer scheme [27].

2.4. Simulation Model of Land Transition. Based on the conversion data under the RCP6 and RCP8.5, which were produced by AIM and MESSAGE model from 2009 to 2050, respectively, the total area of land transitions from grassland to forestland was calculated from 2010 to 2050. They were used by DLS to simulate the future spatial pattern of the conversion of forestland from grassland in Fujian. The DLS model is theoretically based on restrictions of the distribution of land types. It dynamically simulates the macroscopic pattern changes in land cover by classifying the driving factors that influence this pattern. Considering the links among related models of nature, ecology, and economy, we used DLS to spatially allocate the area change in the forestland transition from grassland. Based on spatial statistics data, the probabilities of the transition of grassland to forestland and the probabilities of distribution of this transition were predicted at the pixel level. In the simulation process, we also considered the influence of macroscopic factors such as topography, environment, trade, and institutional arrangement and land management policies to more accurately simulate possible scenarios of pattern changes in land system $[29,30]$.

2.5. Scenario Building and Data Analysis. We took RCP6 as the moderate development scenario of Fujian; it is a stabilization scenario where total radiative forcing is stabilized after 2100 without overshoot by employment of a range of technologies and strategies for reducing greenhouse gas emissions [31, 32]. Grassland area declined while total forested area extent remained constant throughout the century at the global scale [33].

While RCP8.5 is an emissions pathway which reaches a radiative forcing of $8.5 \mathrm{~W} / \mathrm{m}^{2}$ and rising in 2100 , we made it a fast development scenario of Fujian, with a high magnitude of climate change and factors related to higher vulnerability (e.g., higher population growth and lower levels of economic development). It is characterized by increasing greenhouse gas emissions over time representative for scenarios in 


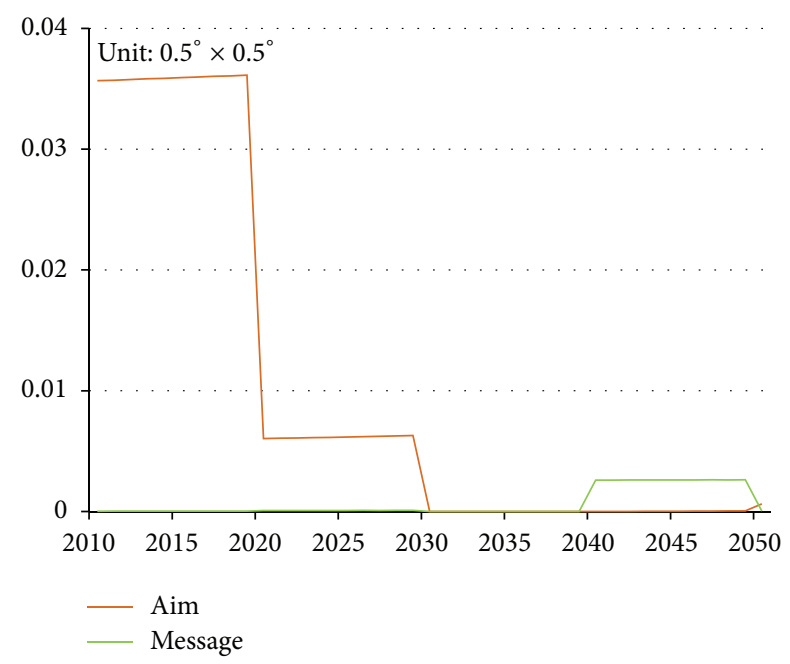

FIGURE 2: Conversion from grassland to forestland under the RCPs scenarios in Fujian province, 2010-2050.

the literature leading to high greenhouse gas concentration levels. The underlying scenario drivers and resulting development path are based on the A2r scenario [34]. An important feature of the RCP8.5 was the increase in cultivated land by about 185 million ha from 2000 to 2050; forest cover declined over the century by 300 million ha from 2000 to 2050 [33].

The transition from grassland to forestland in Fujian is significant under the RCP6 and RCP8.5 scenarios with spatial resolution of $0.5^{\circ} \times 0.5^{\circ}$ (Figure 2). Firstly, the downloaded data was downscaled to $1 \times 1 \mathrm{~km}^{2}$ grid, and then the overlay analysis was taken with the administrative boundary data to calculate the total amount of the transition from grassland to forestland. During 2010-2050, the transition of forestland from grassland presents a soaring trend in 20102020 , followed by a sharp decline in 2020 , when a stable decrease occurs in the next 30 years under the RCP6 scenario, but it is pervasively higher than that of RCP8.5.

\section{Results}

3.1. Impact on Temperature. Temperature differences of nearsurface temperature at 2 meters height $\left(T_{2 \mathrm{~m}}\right)$ of forestland conversion from grassland experiment and nonconversion experiment show the climate effect of the conversion (Figure 3). In summer, the cooling effect has emerged in the conversion area of grassland to forestland. Compared with the other area, the maximum difference of the seasonal average $T_{2 \mathrm{~m}}$ is approximately $0.60^{\circ} \mathrm{C}$ in the conversion area of grassland to forestland, and the regional average $T_{2 \mathrm{~m}}$ decreases by $0.16^{\circ} \mathrm{C}$ with $\mathrm{EI}\left(T_{2 \mathrm{~m}}\right)=2.23$, while in winter, there is a heating effect in the conversion area of grassland to forestland, with the maximum difference of the seasonal average $T_{2 \mathrm{~m}}$ increasing by $0.08^{\circ} \mathrm{C}$, and the average $T_{2 \mathrm{~m}}$ is rising by $0.03^{\circ} \mathrm{C}$ with $\mathrm{EI}\left(T_{2 \mathrm{~m}}\right)=1.93$. On the whole, the annual average $T_{2 \mathrm{~m}}$ decreases by $0.11^{\circ} \mathrm{C}$ in Fujian.

3.2. Impact on Precipitation. Precipitation varies from one region to another (Figure 4); the northwest Fujian was the
TABLE 1: Comparison of the meteorological station observed (OBS) and model simulated annual near-surface temperature at 2 meters height (unit: ${ }^{\circ} \mathrm{C}$ ) and precipitation error (unit: $\mathrm{mm}$ ) over 23 weather stations in Fujian province in 2008.

\begin{tabular}{lccccc}
\hline No. & Station & Latitude & Longitude & $T_{\text {error }}$ & $P_{\text {error }}$ \\
\hline 58726 & Qixianshan & 27.95 & 117.83 & 1.23 & 129.55 \\
58730 & Wuyishan & 27.77 & 118.03 & 0.12 & 8.43 \\
58731 & Pucheng & 27.92 & 118.53 & 0.04 & -2.87 \\
58734 & Jianyang & 27.33 & 118.12 & 1.56 & 51.79 \\
58737 & Jianou & 27.05 & 118.32 & -0.50 & 48.72 \\
58754 & Fuding & 27.33 & 120.20 & 0.76 & -77.27 \\
58820 & Taining & 26.90 & 117.17 & 0.84 & 84.33 \\
58834 & Nanping & 26.65 & 118.17 & -0.32 & 35.78 \\
58846 & Ningde & 26.67 & 119.52 & 1.34 & 67.00 \\
58847 & Fuzhou & 26.08 & 119.28 & 0.98 & 12.47 \\
58853 & Taishan & 27.00 & 120.70 & 0.25 & -28.38 \\
58911 & Changting & 25.85 & 116.37 & 0.56 & 55.00 \\
58918 & Shanghang & 25.05 & 116.42 & -2.01 & 34.00 \\
58921 & Yongan & 25.97 & 117.35 & 0.73 & 74.74 \\
58926 & Tanping & 25.30 & 117.42 & 0.34 & 33.11 \\
58927 & Longyan & 25.10 & 117.03 & 1.62 & -62.94 \\
58931 & Jiuxianshan & 25.72 & 118.10 & 0.28 & 32.61 \\
58933 & Pingnan & 26.92 & 118.98 & -0.15 & 145.00 \\
58944 & Pingtan & 25.52 & 119.78 & 0.37 & 34.49 \\
59126 & Zhangzhou & 24.50 & 117.65 & 0.99 & 10.38 \\
59133 & Chongwu & 24.90 & 118.92 & 0.33 & -27.74 \\
59134 & Xiamen & 24.48 & 118.07 & -0.56 & 54.83 \\
59321 & Dongshan & 23.78 & 117.50 & 0.76 & 74.70 \\
\hline
\end{tabular}

main area where the amount of precipitation increased, while the southeast reverses the case. According to the spatial statistical analysis, the range of the difference of precipitation between TFG case and NOTFG case is $-40 \sim 70 \mathrm{~mm}$, and the majority of the change ranged from $-30 \mathrm{~mm}$ to $50 \mathrm{~mm}$, while the annual average precipitation increased by $46 \mathrm{~mm}$ with EI $(P=4.68)$.

3.3. Validation of the Control Case. We selected 23 meteorological stations' continuous observation data from 2000 to 2008; all of them have passed through the homogenization test. The monthly mean temperature data is provided by the National Meteorological Information Center of China. When assessing its simulation capability, the simulation results were bilinearly interpolated to 23 weather stations, to calculate the average and seasonal temperature of each site.

The errors between the simulations and observations of surface temperature and precipitation are listed in Table 1 , and the $P$ test values are 0.81 and 0.76 , respectively. The errors between the simulations and observations are less than $1.00^{\circ} \mathrm{C}$ except for the Qixianshan, Jianyang, Ningde, Shanghang, and Longyan stations. The relative errors of the annual precipitation are all less than $12 \%$; therefore, we think the simulation result is reliable and presume it will work accordantly well in the future. 


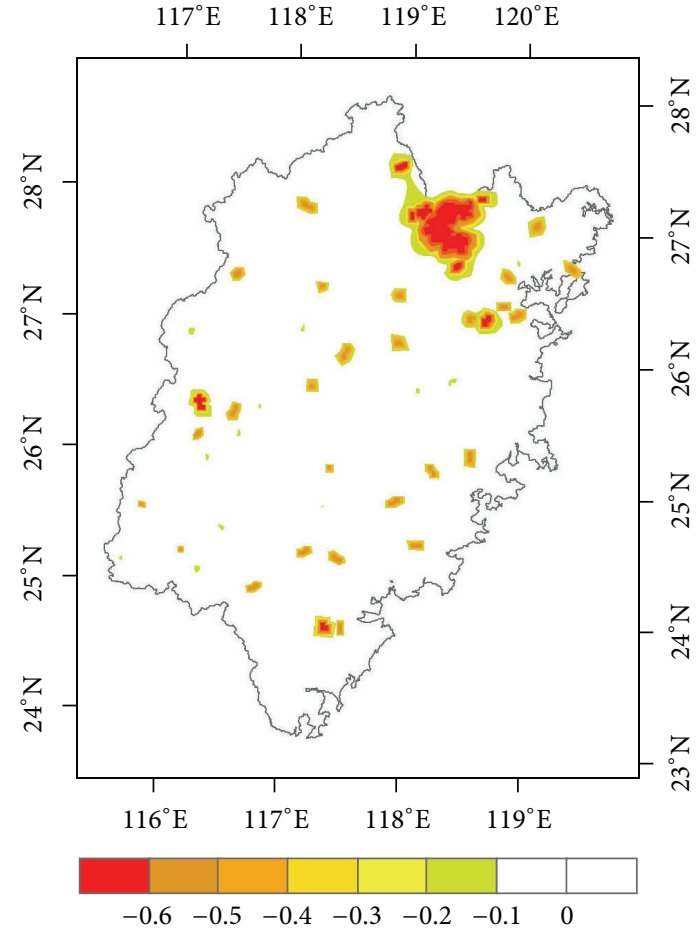

(a)

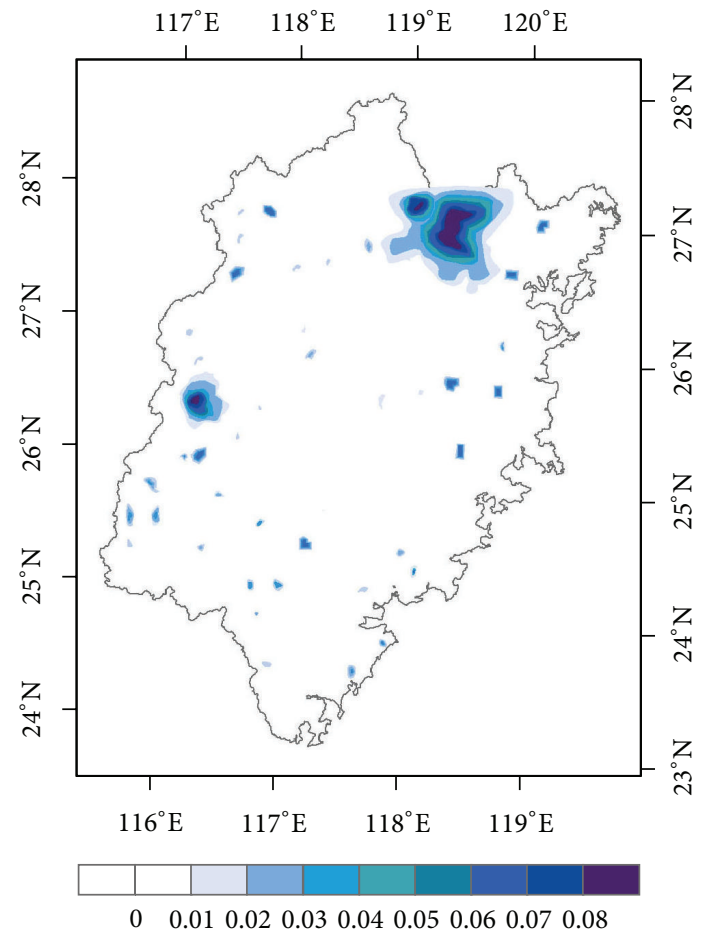

(b)

FIgURE 3: Seasonal difference of near-surface temperature at 2 meters height (unit: ${ }^{\circ} \mathrm{C}$ ) in the experiment of conversion from grassland to forestland in Fujian province, 2000-2008. (a) and (b) identify the temperature difference in summer and winter, respectively.

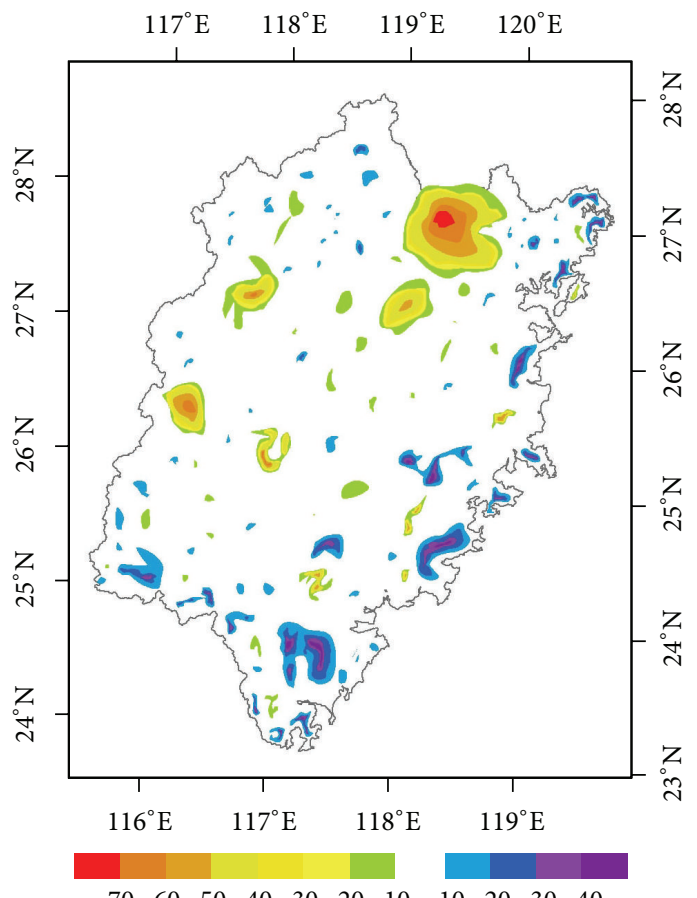

FIGURE 4: Annual average precipitation difference (unit: $\mathrm{mm}$ ) in the experiment of conversion from grassland to forestland in Fujian province, 2000-2008. 


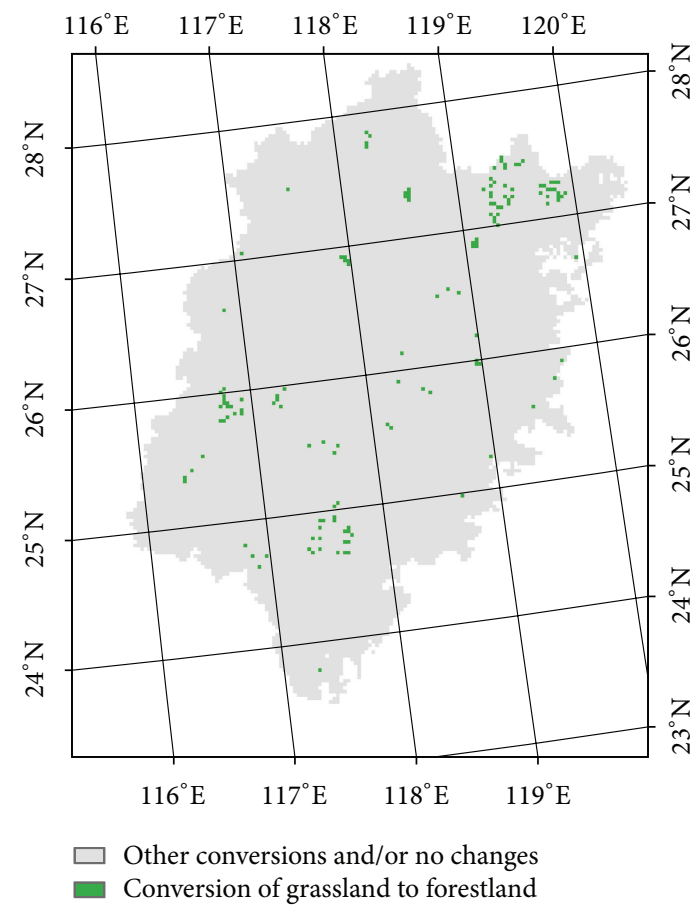

(a)

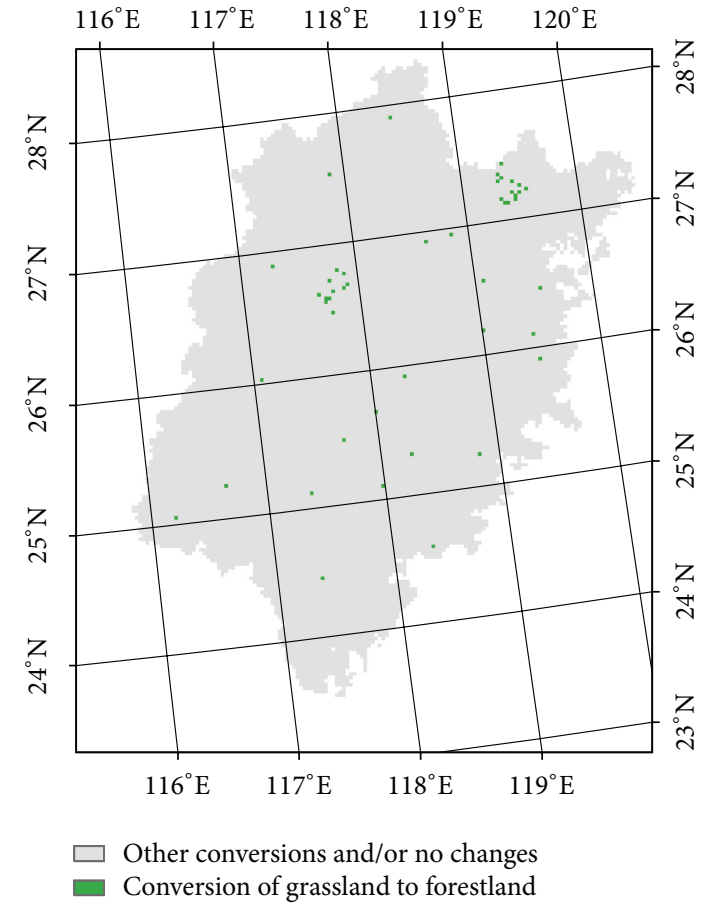

(b)

FIGURE 5: Spatial pattern of the conversion (measured in $3 \mathrm{~km}$ ) from grassland to forestland in 2010-2050 under RCP6 (a) and RCP8.5 (b) in Fujian province.

\subsection{Future Climate Effects Estimation on Surface Temperature} and Precipitation under the RCPs Scenario. Under the two RCPs scenarios (RCP6 and RCP8.5), the spatial pattern of transition of forestland from grassland was simulated with DLS model (Figure 5). It can be seen from Figure 5(a) that the northeast and southwest of Fujian would experience more intensive transition of grassland to forestland than other regions under the RCP6 scenario, and this conversion occurs broadly on the whole regional perspective. While under the RCP8.5 scenario apppeared in Figure 5(b), the transition of grassland to forestland is not as intensive as that of RCP6 scenario; it is mainly concentrated in the northern Fujian.

Then, the two projections of land transition of forestland from grassland data under RCP6 and RCP8.5 were used to estimate the climate effects of that transition in future. And the seasonal $T_{2 \mathrm{~m}}$ change in winter and summer of the two scenarios is calculated between 2010 and 2050 to show the spatial scale of the transition of grassland to forestland (Figure 6). In summer, the conversion of forestland from grassland has a cooling effect under the two climate scenarios. Under the RCP6 scenario, the change of mean $T_{2 \mathrm{~m}}$ is mainly distributed in the north and southwest Fujian and that of the RCP8.5 scenario is primarily concentrated in the central and north region. The change of average $T_{2 \mathrm{~m}}$ is $-0.69^{\circ} \mathrm{C}$ with EI $\left(T_{2 \mathrm{~m}}\right)=3.21$ under RCP6 scenario and $-0.43^{\circ} \mathrm{C}$ with EI $\left(T_{2 \mathrm{~m}}\right)=1.36$ under RCP8.5 scenario in the conversion area of grassland to forestland, while in winter, the average $T_{2 \mathrm{~m}}$ increases $0.06^{\circ} \mathrm{C}$ with EI $\left(T_{2 \mathrm{~m}}\right)=2.86$ under the RCP6 scenario in the converted area; whereas under the RCP8.5 scenario, although winter cooling occurs across the region, there is no obvious concentration area, the change of regional average $T_{2 \mathrm{~m}}$ is $0.01^{\circ} \mathrm{C}$ with $\mathrm{EI}\left(T_{2 \mathrm{~m}}\right)=1.14$.

In order to explore the time scale of the impact of the conversion from grassland to forestland, the every 10-year difference of the $T_{2 \mathrm{~m}}$ and precipitation was calculated from 2010 to 2050 (Figure 7). Both in RCP6 and RCP8.5, the annual average $T_{2}$ decreases as the conversion from grassland to forestland occurs. On the whole, the annual average $T_{2 \mathrm{~m}}$ decreases by $0.57^{\circ} \mathrm{C}$ and $0.21^{\circ} \mathrm{C}$ under the scenarios of RCP6 and RCP8.5, respectively, from 2010 to 2050. The maximum decrease of $T_{2} \mathrm{~m}$ would reach $0.16^{\circ} \mathrm{C}$ in ten years differences, and the minimum value is $0.03^{\circ} \mathrm{C}$ in the two scenarios. Although the overall decline of $T_{2 \mathrm{~m}}$ under the RCP8.5 scenario is lower than that of RCP6, the minimum decrease of $T_{2 \mathrm{~m}}$ under RCP8.5 is higher than $0.03^{\circ} \mathrm{C}$. In terms of the precipitation, there are small fluctuations under the two scenarios, ranging at $-63 \sim 142 \mathrm{~mm}$ and $-51 \sim 109 \mathrm{~mm}$. Meanwhile, the two scenarios would experience an overall increase of precipitation during 2010-2050.

\section{Conclusions and Discussions}

In this paper, climate impacts of historical (2000-2008) and future (2010-2050) land conversion from grassland to forestland were simulated using WRF model, whose result showed this conversion has a significant impact on regional climate. The result shows that during 2010-2050, the conversion from grassland to forestland leads to the decrease of annual average 


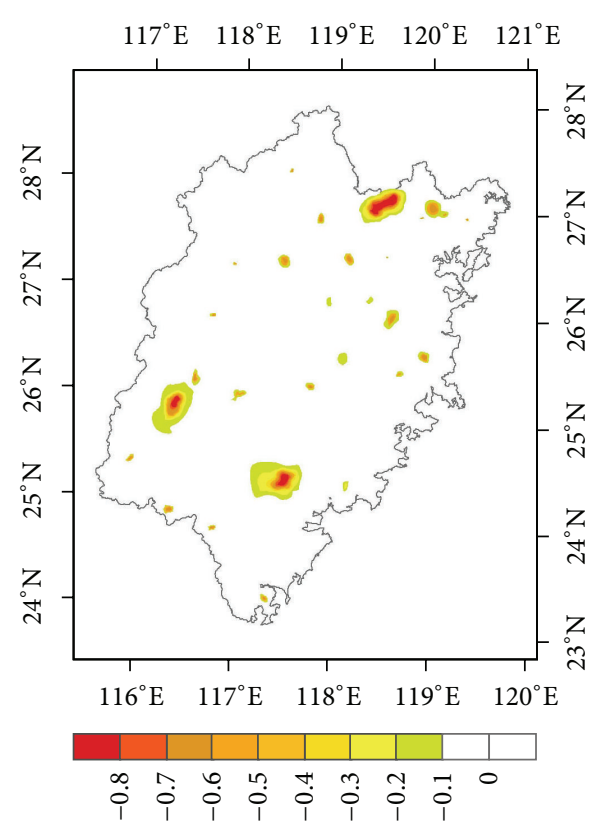

(a)

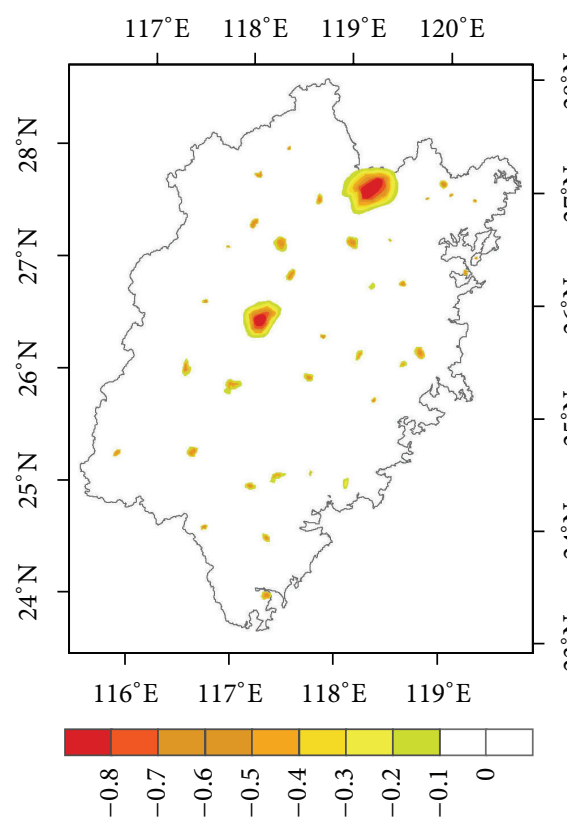

(c)

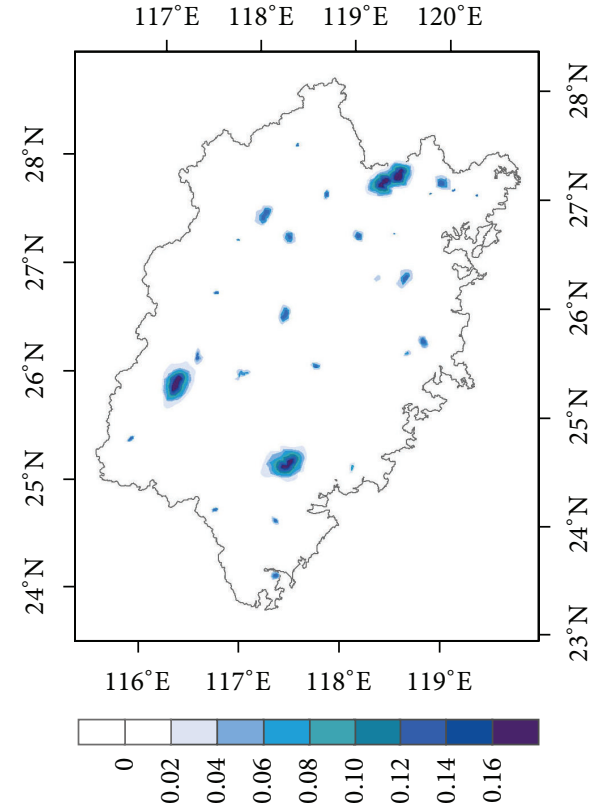

(b)

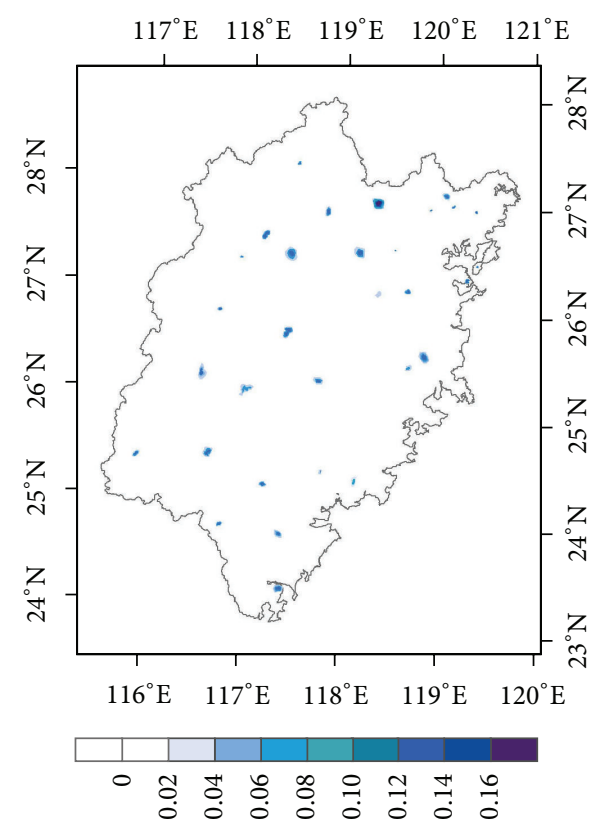

(d)

FIGURE 6: Seasonal average near-surface temperature at 2 meters height (unit: ${ }^{\circ} \mathrm{C}$ ) change in $2010-2050$. (a) Summer temperature change under RCP6 scenario; (b) winter temperature change under RCP6 scenario; (c) summer temperature change under RCP8.5 scenario; (d) winter temperature change under RCP8.5 scenario.

$T_{2 \mathrm{~m}}$ by $0.57^{\circ} \mathrm{C}$ and $0.21^{\circ} \mathrm{C}$ under the RCP6 and RCP8.5 scenarios, respectively, and the value of EI $\left(T_{2 \mathrm{~m}}\right)$ in summer (represents cooling) is higher than that in winter (represents heating) in the experiments, indicating that the summer cooling efficiency is higher than winter heating efficiency in our study. The mechanism is that grassland reflects more solar radiation than forest in Fujian does, which is a very efficient absorber and scatterer of short-wavelength radiation [35]. Consequently, the net energy absorbed by the surface was increased as a result of the conversion from grassland to forestland, which would result in a temperature increase but this is offset by an increase in evaporative cooling for the fact that the fact that the area is abundant with sunlight and heating resources. So, there is an overall decrease in temperature.

In spite of the change of precipitation fluctuates from one region to another as the conversion from grassland to forestland occurs in both historical and future land conversion 


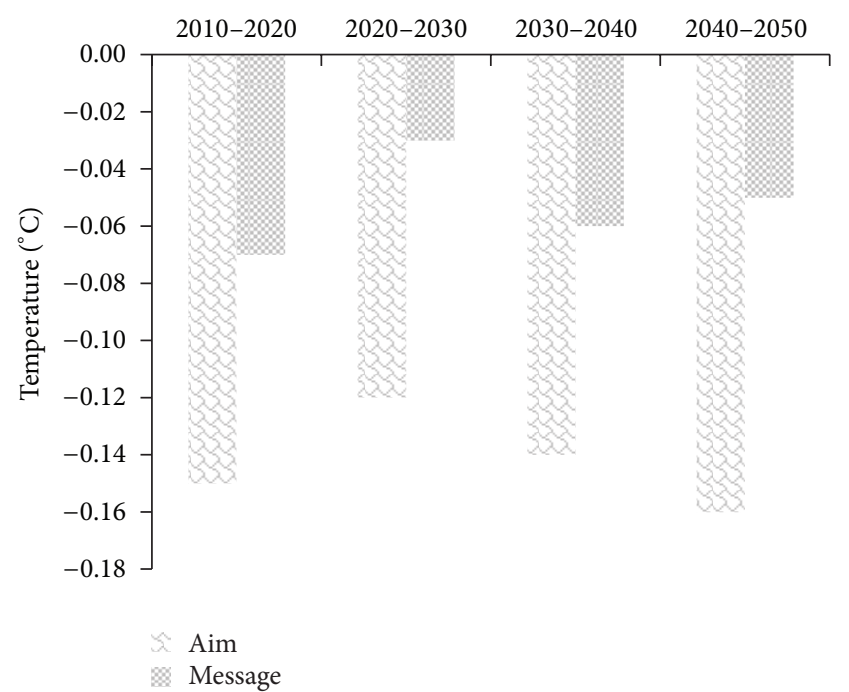

(a)

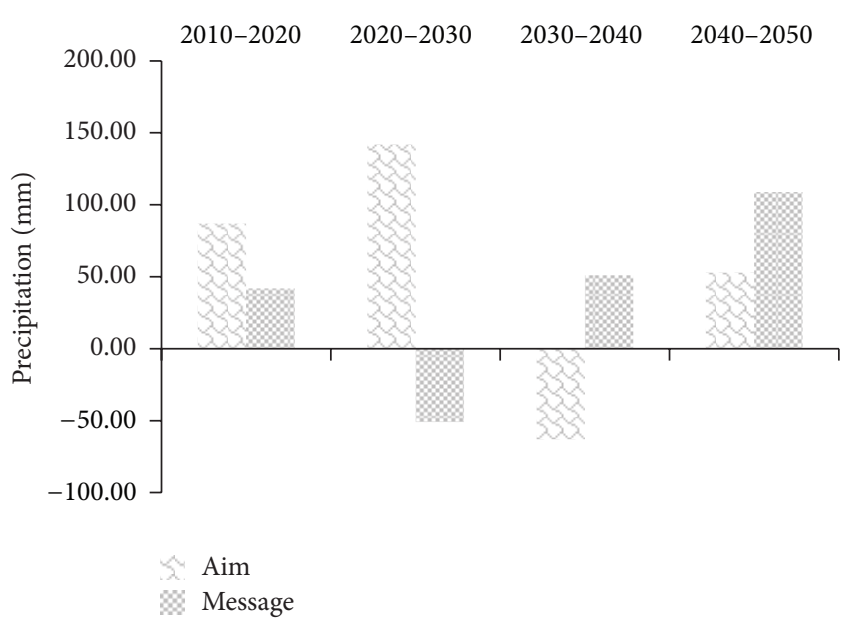

(b)

FIgURE 7: Climate impacts of the conversion from grassland to forestland under the RCP6 and RCP8.5 scenarios from 2010 to 2050 in Fujian province. (a) Near-surface temperature change at 2 meters height (unit: ${ }^{\circ} \mathrm{C}$ ); (b) precipitation change (unit: $\mathrm{mm}$ ).

experiment in Fujian, it is increased on the whole. It is for the fact that the precipitation within Fujian originates from two sources, one is the recycling of water vapor released during evapotranspiration and the other is moisture flux convergence into this area. The water vapor released is increased as the conversion from grassland to forestland occurs because of the enhanced evapotranspiration in Fujian, while the increase in moisture flux convergence is due mainly to decreased albedo caused by the transition of forestland from grassland, thus affecting the reflectivity of a surface by absorbing more heat, and decreased albedo reduces the available energy for upward turbulent transfer of latent energy [35], which in turn carries moisture from forest trees into atmosphere, where it condenses as rain and the convergence zone is induced. So, the precipitation increases on the whole.

We have only focused on the physical impact of forestland transition from grassland change in this paper, but the climate change is a very complicated process and many factors may influence it. Summarizing the effects of land cover change on climate has been difficult because different biogeophysical effects offset each other in terms of climate impacts [36], and, on global and annual scales, regional impacts are often of opposite sign and are therefore not well represented in annual global average statistics $[36,37]$. Besides, the uncertainty will remain in projections of future climates for the foreseeable future. The climate modeling community is aware of these uncertainties and some innovative approaches to assess their magnitude have recently been explored [38, 39]. Sensitive study in different land surface schemes has been conducted to better estimate precipitation in WRF [40], but more extensive modeling experiments are needed in the WRF simulation process. Besides, the precise contribution of the land cover change to the global climate change remains a controversial but growing concerned issue [41]. In addition, pollutant release is another important factor that affects the radiation process and thus affects precipitation over afforestation areas. Future studies utilizing a wide range of scenarios for climate, land use, and realistic vegetation parameters to quantify the effects of different factors on regional climate are essential. Additionally, with the increasing available computational resources, more land transition runs would be the optimal way to assess the large scale climatic effects land use/cover change.

\section{Acknowledgments}

This research was supported by the Project of the National Natural Science Foundation of China (Grant no. 41071343) and the National Basic Research Program of China (973 Program) (Grant no. 2010CB950904).

\section{References}

[1] R. A. Pielke, R. Avissar, M. Raupach, A. J. Dolman, X. Zeng, and A. S. Denning, "Interactions between the atmosphere and terrestrial ecosystems: influence on weather and climate," Global Change Biology, vol. 4, no. 5, pp. 461-475, 1998.

[2] L. Bounoua, R. DeFries, G. J. Collatz, P. Sellers, and H. Khan, "Effects of land cover conversion on surface climate," Climatic Change, vol. 52, no. 1-2, pp. 29-64, 2002.

[3] V. Brovkin, A. Ganopolski, M. Claussen, C. Kubatzki, and V. Petoukhov, "Modelling climate response to historical land cover change," Global Ecology and Biogeography, vol. 8, no. 6, pp. 509517, 1999.

[4] G. Bonan, D. Pollard, and L. Starley, "Effects of boreal forest vegetation on global climate," Nature, vol. 359, no. 6397, pp. 716$718,1992$.

[5] K. Thompson, "Forests and climate change in America: some early views," Climatic Change, vol. 3, no. 1, pp. 47-64, 1980.

[6] R. Dickinson, P. Kennedy, and A. Henderson-Sellers, Biosphereatmosphere transfer scheme (BATS) version le As coupled to the NCAR community climate model, National Center for Atmospheric Research, Climate and Global Dynamics Division, Boulder, Colo, USA, 1993.

[7] A. Betts and J. Ball, "Albedo over the boreal forest," Journal of Geophysical Research D, vol. 102, no. 24, pp. 28901-28909, 1997. 
[8] S. Solomon, D. Qin, M. Manning et al., IPCC. Climate Change 2007: the Physical Science Basis. Contribution of Working Group I to the 4th Assessment Report of the Intergovernmental Panel on Climate Change, Cambridge University Press, Cambridge, UK, 2007.

[9] G. Thomas and P. R. Rowntree, "The boreal forests and climate," Quarterly Journal of the Royal Meteorological Society, vol. 118, no. 505, pp. 469-497, 1992.

[10] S. Chalita and H. Le Treut, "The albedo of temperate and boreal forest and the Northern Hemisphere climate: a sensitivity experiment using the LMD GCM," Climate Dynamics, vol. 10, no. 4-5, pp. 231-240, 1994.

[11] G. B. Bonan, "Effects of land use on the climate of the United States," Climatic Change, vol. 37, no. 3, pp. 449-486, 1997.

[12] T. Chase, R. Pielke, T. G. F. Kittel, R. R. Nemani, and S. W. Running, "Simulated impacts of historical land cover changes on global climate in northern winter," Climate Dynamics, vol. 16, no. 2-3, pp. 93-105, 2000.

[13] Z. Pan, E. Takle, M. Segal, and R. Arritt, "Simulation of potential impacts of man-made land use changes on U.S. summer climate under various synoptic regimes," Journal of Geophysical Research D, vol. 104, no. 6, pp. 6515-6528, 1999.

[14] R. Betts, "The impact of land use on the climate of present day," World Meteorological Organization-Publications-WMO TD, no. 28, pp. 7.11-7.12, 1999.

[15] Y. C. Sud, G. K. Walker, J.-H. Kim, G. E. Liston, P. J. Sellers, and W. K.-M. Lau, "Biogeophysical consequences of a tropical deforestation scenario: a GCM simulation study," Journal of Climate, vol. 9, no. 12, pp. 3225-3247, 1996.

[16] J. Shukla, C. Nobre, and P. Sellers, "Amazon deforestation and climate change," Science, vol. 247, no. 4948, pp. 1322-1325, 1991.

[17] J. Lean and D. A. Warrilow, "Simulation of the regional climatic impact of Amazon deforestation," Nature, vol. 342, no. 6248, pp. 411-413, 1989.

[18] Y. Xue, "The impact of desertification in the Mongolian and the Inner Mongolian grassland on the regional climate," Journal of Climate, vol. 9, no. 9, pp. 2173-2189, 1996.

[19] X. Gao, Y. Luo, W. Lin, Z. Zhao, and F. Giorgi, "Simulation of effects of land use change on climate in China by a regional climate model," Advances in Atmospheric Sciences, vol. 20, no. 4, pp. 583-592, 2003.

[20] J. Jin, S. Lu, S. Li et al., "Impact of land use change on the local climate over the Tibetan plateau," Advances in Meteorology, vol. 2010, Article ID 837480, 6 pages, 2010.

[21] S. Liu, Y. Peng, and W. Wang, "Analysis of the situation and mechanism of Land Use conversion in Southeast Coastal area," Journal of Natural Resources, vol. 20, no. 3, pp. 333-339, 2005.

[22] X. Xu, J. Liu, and D. Zhuang, "Spatial-temporal characteristics and driving forces of woodland resource changes in China," Journal of Beijing Forestry University, vol. 26, no. 1, pp. 41-46, 2004.

[23] J. Liu, Z. Zhang, X. Xu et al., "Spatial patterns and driving forces of land use change in China during the early 21st century," Journal of Geographical Sciences, vol. 20, no. 4, pp. 483-494, 2010.

[24] J. Liu, D. Zhuang, D. Luo, and X. Xiao, "Land-cover classification of China: integrated analysis of AVHRR imagery and geophysical data," International Journal of Remote Sensing, vol. 24, no. 12, pp. 2485-2500, 2003.

[25] C. Wang, D. Zhao, Y. Zhan et al., "Land cover classification with MODIS data in China," in Proceedings of the 2nd International Conference on Earth Observation for Global Changes, vol.
747102, pp. 1-8, International Society for Optics and Photonics, 2009.

[26] W. D. Collins, P. J. Rasch, B. A. Boville et al., "Description of the NCAR community atmosphere model (CAM 3.0)," NCAR Technical Notes NCAR/TN-464+ STR, 2004.

[27] S. Hong and H. Pan, "Nonlocal boundary layer vertical diffusion in a medium-range forecast model," Monthly Weather Review, vol. 124, no. 10, pp. 2322-2339, 1996.

[28] G. A. Grell and D. Dévényi, "A generalized approach to parameterizing convection combining ensemble and data assimilation techniques," Geophysical Research Letters, vol. 29, no. 14, pp. 381$384,2002$.

[29] X. Deng, Q. Jiang, H. Su, and F. Wu, "Trace forest conversions in Northeast China with a 1-km area percentage data model," Journal of Applied Remote Sensing, vol. 4, no. 1, Article ID 041893, 2010.

[30] X. Deng, J. Huang, S. Rozelle, and E. Uchida, "Cultivated land conversion and potential agricultural productivity in China," Land Use Policy, vol. 23, no. 4, pp. 372-384, 2006.

[31] J. Fujino, R. Nair, M. Kainuma, T. Masui, and Y. Matsuoka, "Multi-gas mitigation analysis on stabilization scenarios using aim global model," Energy Journal, vol. 27, pp. 343-353, 2006.

[32] Y. Hijioka, Y. Matsuoka, H. Nishimoto, T. Masui, and M. Kainuma, "Global GHG emission scenarios under GHG concentration stabilization targets," Journal of Global Environment Engineering, vol. 13, pp. 97-108, 2008.

[33] G. Hurtt, L. Chini, S. Frolking et al., "Harmonization of land-use scenarios for the period 1500-2100: 600 years of global gridded annual land-use transitions, wood harvest, and resulting secondary lands," Climatic Change, vol. 109, no. 1, pp. 117-161, 2011.

[34] K. Riahi, A. Grübler, and N. Nakicenovic, "Scenarios of longterm socio-economic and environmental development under climate stabilization," Technological Forecasting and Social Change, vol. 74, no. 7, pp. 887-935, 2007.

[35] J. Lean and D. A. Warrilow, "Simulation of the regional climatic impact of Amazon deforestation," Nature, vol. 342, no. 6248, pp. 411-413, 1989.

[36] R. Pielke, G. Marland, R. Betts et al., "The influence of landuse change and landscape dynamics on the climate system: relevance to climate-change policy beyond the radiative effect of greenhouse gases," Philosophical Transactions of the Royal Society A, vol. 360, no. 1797, pp. 1705-1719, 2002.

[37] J. Feddema, K. Oleson, G. Bonan et al., "A comparison of a GCM response to historical anthropogenic land cover change and model sensitivity to uncertainty in present-day land cover representations," Climate Dynamics, vol. 25, no. 6, pp. 581-609, 2005.

[38] X. Deng, C. Zhao, and H. Yan, "Systematic modeling of impacts of land use and land cover changes on regional climate: a review," Advances in Meteorology, vol. 2013, Article ID 317678, 11 pages, 2013.

[39] D. A. Stainforth, T. Aina, C. Christensen et al., "Uncertainty in predictions of the climate response to rising levels of greenhouse gases," Nature, vol. 433, no. 7024, pp. 403-406, 2005.

[40] J. Jin, L. Miller, and N. Schlegel, "Sensitivity study of four land surface schemes in the WRF model," Advances in Meteorology, vol. 2010, Article ID 167436, 11 pages, 2010.

[41] F. Wu, J. Zhan, H. Yan et al., "Land cover mapping based on multisource spatial data mining approach for climate simulation: a case study in the farming-pastoral ecotone of North China," Advances in Meteorology, vol. 2013, Article ID 520803, 12 pages, 2013. 

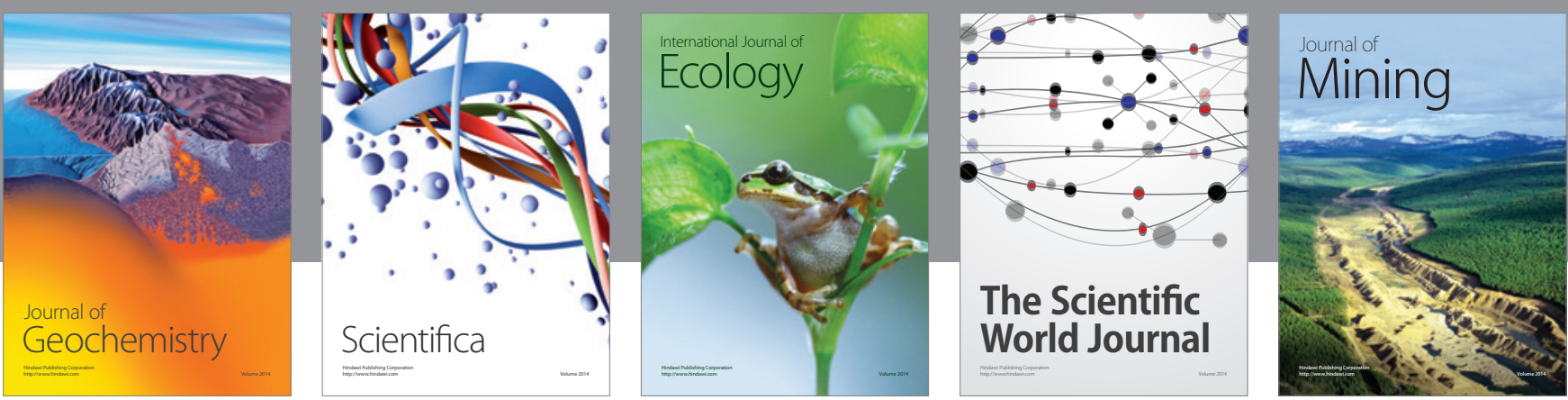

The Scientific World Journal
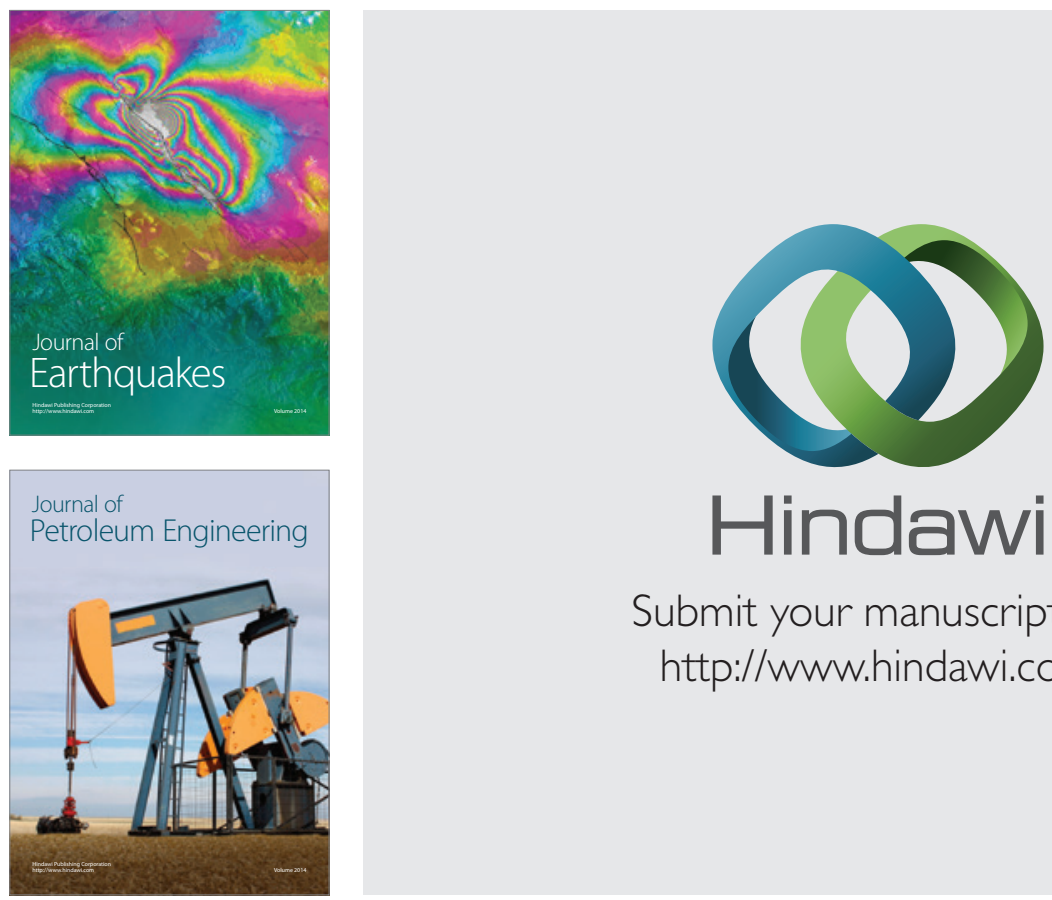

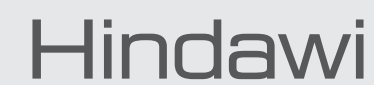

Submit your manuscripts at

http://www.hindawi.com
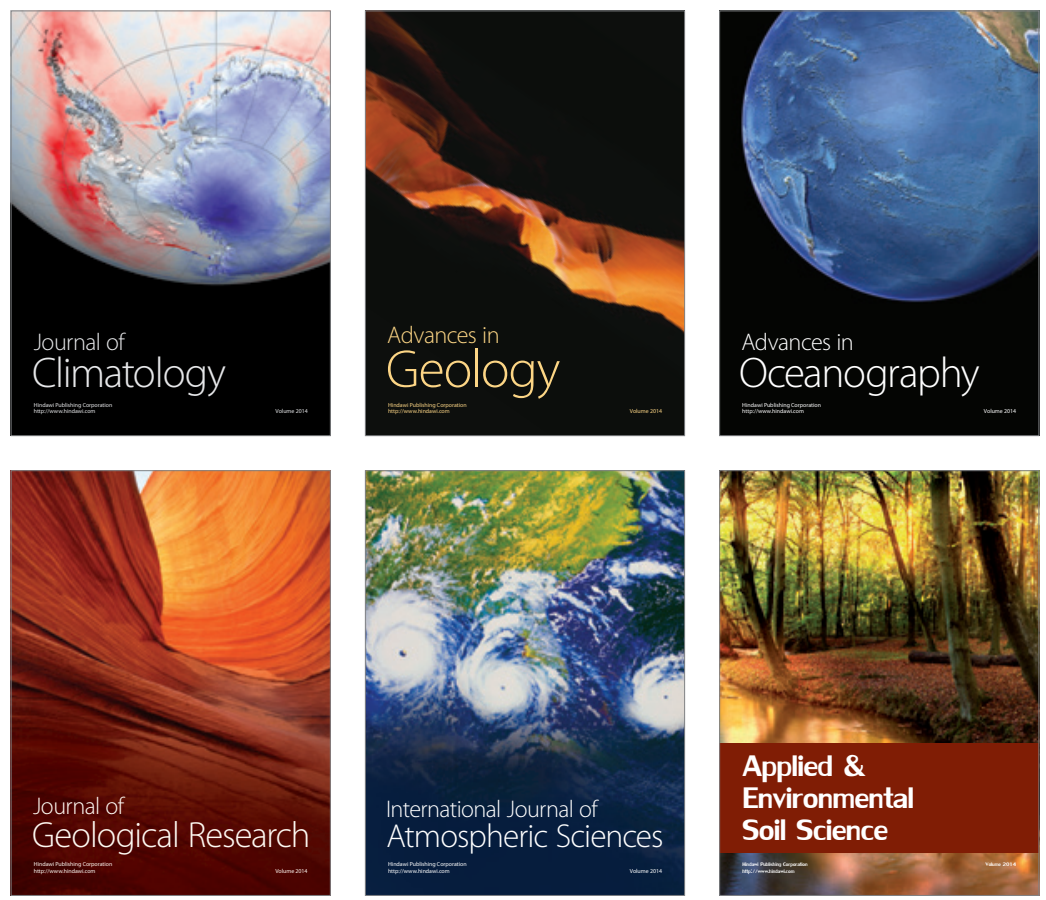
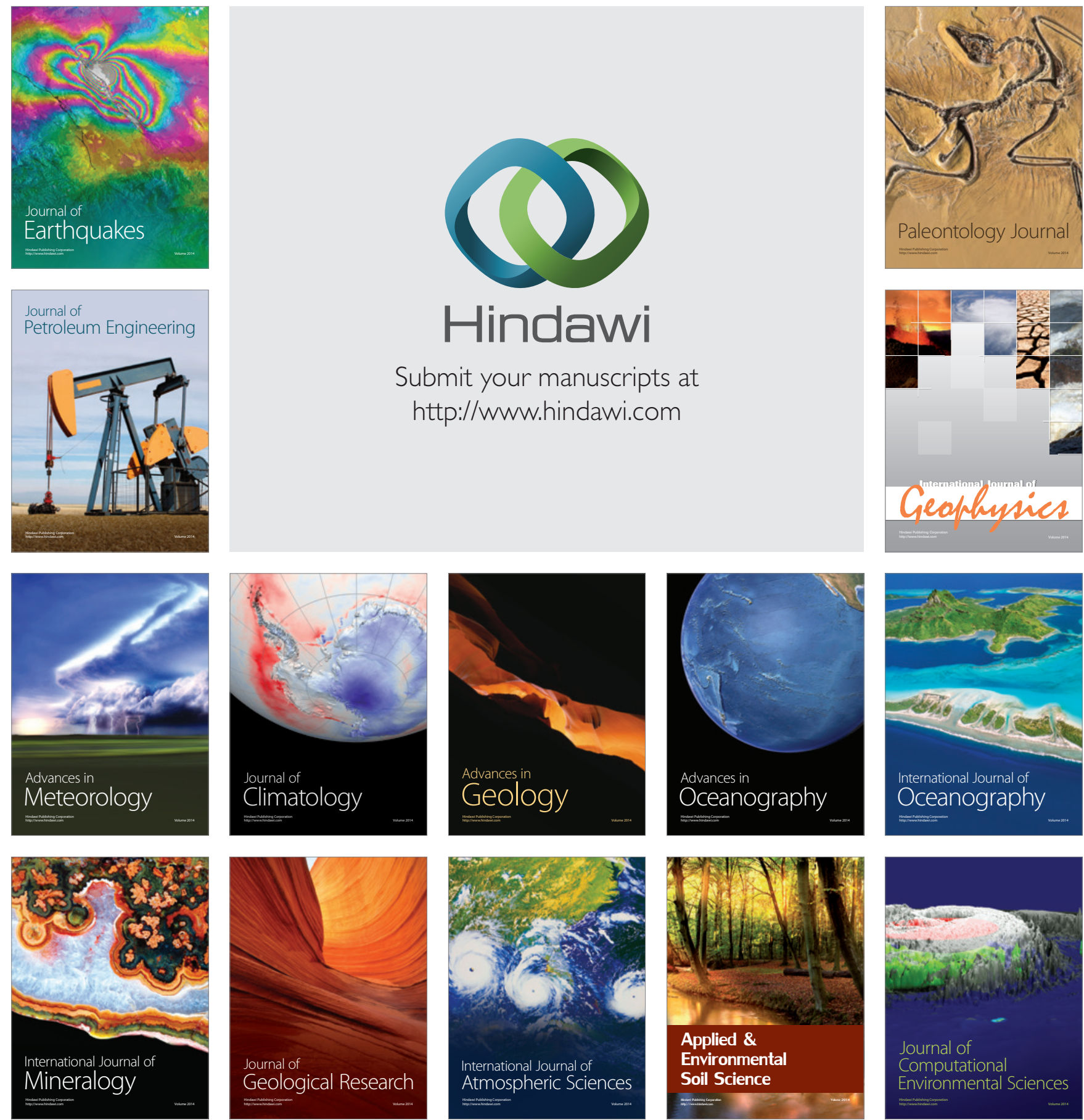